down to a specification of the skin sutures, seems unnecessary. The section dealing with the important subject of common duct strictures describes well the operative methods but does not discuss the prognosis nor the significance of cholangitis in this condition.

This is a useful book which is well worth reading by all who practise abdominal surgery. It is, furthermore, readable. It is a pity that there are a few slightly inadequate sections in a book of this price but these are to some extent compensated by the excellent bibliography.

\section{A MANUAL OF PRACTICAL OBSTETRICS}

By the late O'Donel Browne, M.B., M.A.O., M.A., Litt.D., F.R.C.P.I., F.R.C.O.G. Edited and largely rewritten by J. G. GallaGHER, M.D., M.A.O., F.R.C.P.I., M.R.C.O.G. Third Edition. Pp. viii +265 , with 203 illustrations. Bristol: John Wright \& Sons Ltd. I956. 37s. 6d.

This book falls between several stools. It tries to be a book on practical obstetrics and at the same time to enter into many theoretical considerations.

As a consequence, it loses its value as a work of practical advice or as a textbook of obstetrics. In addition, there are a number of lapses. For instance, the writer appears to recommend that the second stage of labour in a primigravida should be allowed to last three hours before interference is indicated and he thinks that the head is not likely to have appeared between the labia for two hours.

He recommends Credé's technique in the third stage of labour which most authorities now warn against because of the likelihood of producing shock.

Drawings are shown of how to plug the uterus, which again should not be taught too facilely. As chapter succeeds chapter, one can find similar criticisms. In fact, by and large, I do not think this book is to be recommended.

\section{E.E.P.}

\section{ANATOMICAL TECHNIQUES}

By D. H. Tompsett, B.Sc., Ph.D. Pp. xvi +240 , with 83 illustrations. Edinburgh: E. \& S. Livingstone Ltd. 1956. 35 s.

This book contains an account of many of the more recent techniques which are used for the preparation and mounting of macroscopic anatomical specimens for a museum. The principal techniques described are those of dissection, the making of perspex containers, and the preparation of casts in synthetic resins of blood vessels, the ventricles of the brain and other cavities. There is a short but useful chapter on the illustration of anatomical dissections, and Miss Jessie Dobson provides an interesting historical introduction. Although designed for anatomical specimens, most of the techniques described would be of equal value in the preparation and mounting of pathological material.

The methods are those which Dr. Tompsett has developed in recent years at the Royal College of Surgeons, and those who have seen the very beautiful and instructive specimens which have been added to the anatomical collection at the College will be in no doubt about their value and effectiveness. They are described in great detail, with no attempt to conceal the difficulties, or to underestimate the patience and skill which are necessary to produce really first-class results. More important perhaps is the fact that there is no concealment of the many small but essential steps of a practical nature which must be followed meticulously if success is to be achieved. A most useful feature, often lacking in books of this kind, is a list of sources from which all the instruments, materials or apparatus used, can be obtained.

The book is a notable addition to the literature of craftsmanship; it will be invaluable to museum curators and technicans, and of considerable general interest to anyone who uses an anatomical or pathological museum.

\section{MODERN VIEWS ON THE SECRETION OF URINE}

The Cushny Memorial Lectures

Edited by F. R. Winton, M.A., M.D., D.Sc. Pp. 292, with ro illustrations. London: J. \&, A. Churchill. I956. 30s.

To commemorate the work of Prof. A. R. Cushny (who held the Chair of Pharmacology at University College, London, from 1905 to 1918) ten lectures were delivered there in 1955 by distinguished speakers. Of these, eight are either still working in the College or in U.C.H., or have done so in the past.

This book, therefore, very largely represents an indirect tribute to a great man by workers both in the field and in the school in which his leadership was inspiring. The lectures deal with both physiological and clinical aspects of renal function. Very complete reviews of recent work on the mechanism of normal urine formation are given by Dicker, Eggleton and Pickford. Prof. Winton contributes an important chapter on Pressures and Flows in the Kidney, and L. E. Bayliss describes Secretion. (This would have interested Cushny most of all !) Clinicians will find the very able reviews of Nabarro (The influence of the adrenal cortex) and of Prof. Rosenheim (Functional aspects of Renal Failure) most valuable. A very interesting chapter by Harris deals with Genetic aspects of Tubular Function-much of this work has come from other workers at U.C.H., notably Prof. Dent. (Surely congenital pitressin-sensitive diabetes insipidus is rare enough to merit a reference !) Prof. McCance and E. M. Widdowson (Metabolism and Renal Function in the First Two Days of Life) and Prof. Bull (Osmotic Diuresis 